\title{
Removal of hexavalent chromium from aqueous solution by barium ion cross-linked alginate beads
}

Sesil Uzașç, Filiz Tezcan and F. Bedia Erim*

Istanbul Technical University, Department of Chemistry, 34469 Maslak, Istanbul, Turkey

\begin{abstract}
Barium ion cross-linked alginate beads have shown great affinity to toxic hexavalent chromium ions in aqueous solution, contrary to the traditional calcium alginate beads. The adsorption experiments were carried out by the batch contact method. The optimal $\mathrm{pH}$ for removal was found to be $\mathrm{pH}$ 4. The equilibrium was established in $4 \mathrm{~h}$ and the removal efficiency of chromium (VI) was found as $95 \%$. The adsorption data fit well with Langmuir and Freundlich isotherms. The maximum chromium (VI) adsorption capacity determined from Langmuir isotherm was $36.5 \mathrm{mg} / \mathrm{g}$ dry alginate beads. Our study suggests that barium alginate beads can be used as cost-effective and efficient adsorbents for the removal of chromium (VI) from contaminated waters.
\end{abstract}

